\title{
Cardiovascular Effects of Surfactant Suspensions Given by Tracheal Instillation to Premature Lambs
}

\author{
ALAN JOBE, ${ }^{(20)}$ HARRIS JACOBS, MACHIKO IKEGAMI, AND SALLY JONES
}

Harbor-UCLA Medical Center, UCLA School of Medicine, Torrance, California, USA

\begin{abstract}
Summary
After delivery by cesarean section at 133-136 days gestational age, 18 lambs were supported with infant ventilators. Peak inspiratory pressure was the only ventilator setting that was changed in an attempt to normalize $\mathbf{P C O}_{2}$. The lambs were retrospectively divided into two groups based on their respiratory status before treatment. Ten lambs with $\mathrm{PCO}_{2}$ values of $38 \pm 2 \mathrm{mmHg}$ (mean \pm S.E.) at $5 \mathrm{~h}$ of age were treated with a 15-ml suspension containing $50 \mathrm{mg}$ natural sheep surfactant lipid/ $\mathrm{kg}$ body weight. After surfactant instillation, $\mathrm{pH}$ fell, $\mathrm{PCO}_{2}$ increased and compliance/ $\mathrm{kg}$ decreased transiently. Surfactant treatment did not reduce the respiratory support that these lambs required. Eight lambs with $\mathrm{PCO}_{2}$ values of $68 \pm 3 \mathrm{mmHg}$ at $3 \pm 0.8 \mathrm{~h}$ of age responded to surfactant instillation with a decrease in $\mathrm{PCO}_{2}$ and an increase in $\mathrm{PO}_{2}$ and $\mathrm{pH}$. In both groups of lambs heart rates, mean aortic pressures, and mean pulmonary artery pressures changed little after surfactant instillation. Cardiac outputs and regional blood flows measured before and after surfactant treatment were unchanged. Instillation of surfactant suspensions to premature lambs did not adversely affect cardiovascular status; however, some lambs did have a transient deterioration of lung function after surfactant instillation.
\end{abstract}

\section{Abbreviations}

RDS, respiratory distress syndrome

Fr., French

Suspensions of surfactant given via the trachea either at birth or after the onset of respiratory failure dramatically improve lung function in premature monkeys (5), rabbits (6), and lambs (1). This encouraging experience has resulted in two clinical trials of the administration of surfactant suspensions as therapy for infants with RDS (7, 17). A concern is the safety of delivering surfactant suspended in a large volume of aqueous solution to infants in respiratory failure (15). The fluid volume could further compromise lung function and/or secondarily affect cardiovascular function (13). Prematurely delivered lambs have a syndrome of respiratory failure that is physiologically similar to RDS and results in histologic changes comparable to those observed in infants with RDS (18). We have assessed cardiovascular function in prematurely delivered lambs before and after surfactant treatment by tracheal instillation.

\section{MATERIALS AND METHODS}

Animal preparation. Eighteen lambs were delivered by Cesarean section from date-mated Western mixed breed ewes carrying twins at 133-136 days gestational age. The ewes, each weighing approximately $40 \mathrm{~kg}$, were sedated with intramuscular injections of 800 $\mathrm{mg}$ ketamine and $3 \mathrm{mg}$ atropine sulfate. The ewes then received spinal-epidural anesthesia with $4 \mathrm{ml} 2 \%$ lidocaine and $4 \mathrm{ml} 0.5 \%$ marcaine. The head and neck of each lamb were exposed through an uterine incision and a 5-mm endotracheal tube was secured by tracheotomy (12). After sampling fetal lung fluid, each lamb was delivered, a sample of cord venous blood for blood gas and $\mathrm{pH}$ analysis was taken, and the lamb was ventilated with $100 \%$ oxygen with an anesthesia bag at peak inspiratory pressures of $30 \mathrm{cmH}_{2} \mathrm{O}$ (12). The lambs were weighed and then ventilated with humidified and warmed $100 \%$ oxygen on Sechrist pressure limited infant ventilators with the following initial settings: rate, 20 breaths $/ \mathrm{min}$; inspiratory time, $1 \mathrm{sec}$; positive end expiratory pressure, $2 \mathrm{cmH}_{2} \mathrm{O}$; peak inspiratory pressure, $28 \mathrm{cmH}_{2} \mathrm{O}$; flow, 8 liter/min. The lambs were paralyzed with pancuronium bromide given through a $5 \mathrm{Fr}$. catheter placed in the distal aorta via an umbilical artery. This catheter was used for continuous blood pressure and heart rate recording and for frequent arterial blood gas and $\mathrm{pH}$ measurements. Only the peak inspiratory pressure of the ventilator was changed in an attempt to keep the $\mathrm{PCO}_{2}$ between $30-40 \mathrm{mmHg}$; no other ventilator changes were made for the duration of the experiment. Each lamb received an infusion of $10 \%$ dextrose at $100 \mathrm{cc} / \mathrm{kg} \cdot 24 \mathrm{~h}$, and body temperature was maintained with radiant warmers and heat lamps. The tidal volume of each lamb was measured with a Fleisch pneumotachygraph (12). Compliance $/ \mathrm{kg}$ was calculated as $\mathrm{ml}$ tidal volume $/ \mathrm{kg}$ body weight divided by the difference between peak inspiratory pressure and positive end expiratory pressure.

Shortly after birth, a $3.5 \mathrm{Fr}$. infant feeding tube was passed into the left ventricle via the right carotid artery and secured. A second 3.5 Fr. infant feeding tube or a 4 Fr. Swan Ganz balloon catheter was passed into the pulmonary artery. Catheter positions were verified by pressure wave form. The left ventricular and pulmonary artery catheters were continuously infused at $1 \mathrm{ml} / \mathrm{h}$ with saline containing 1 unit heparin/ml. Pressures were recorded continuously from the aortic and pulmonary artery catheters using a Beckman Dynograph Recorder, Model R611 and Beckman transducers. Mean pressures were measured electronically.

Surfactant treatment. All lambs were treated by tracheal instillation with $50 \mathrm{mg}$ natural sheep surfactant lipid/kg suspended in $15 \mathrm{ml}$ water. The surfactant was isolated from lung lavage from adult sheep as previously reported (12). This surfactant was very effective at improving lung function in premature lambs delivered at 120 days gestational age. Surface properties and composition have been reported (12). To instill the surfactant suspension, the lamb was disconnected from the ventilator and the 15-ml suspension was injected into the endotracheal tube over $5 \mathrm{sec}$ as the lamb was rotated. The endotracheal tube then was reconnected to the ventilator within $10 \mathrm{sec}$ with no changes in ventilator settings. The lamb was manually rotated for about $15 \mathrm{sec}$ after surfactant instillation and placed with the sternum down on the bed for the duration of the experiment. The lambs were treated arbitrarily with surfactant at $5 \mathrm{~h}$ of age if $\mathrm{PCO}_{2}$ values were within the normal range $(n=10)$. If $\mathrm{PCO}_{2}$ values were greater than $60 \mathrm{mmHg}$, despite peak inspiratory pressures over $30 \mathrm{cmH}_{2} \mathrm{O}$, the lambs were treated before $5 \mathrm{~h}$ of age $(n=5)$. Three additional lambs were also in respiratory failure, but were not treated until approximately $5 \mathrm{~h}$ of age. 
Radiolabeled microsphere injections. Radiolabeled microsphere injections were used to detect changes in blood flow before and after surfactant treatment. Shortly before surfactant treatment, and about $20 \mathrm{~min}$ and $3 \mathrm{~h}$ after surfactant treatment, each lamb received an injection into the left ventricle of $15 \pm 2 \mu \mathrm{m}$ (mean \pm S.D.) diameter microspheres (New England Nuclear) labeled with $\left[{ }^{57} \mathrm{Co}\right],\left[{ }^{113} \mathrm{Sn}\right]$ or $\left[{ }^{46} \mathrm{Sc}\right](9)$. Starting just before the injection, a reference sample was withdrawn at a rate of $6 \mathrm{ml} / \mathrm{min}$ for $2 \mathrm{~min}$ into a heparinized glass syringe from the aortic catheter with a Harvard pump. The blood volume of each reference sample immediately was divided into three scintillation vials and sequential rinses of the syringe were added to the vials. After sacrifice, the organs of each lamb were weighed. Each adrenal was placed in a separate vial for counting whereas all other organs and the carcass were carbonized before counting (9). The radioactivity in the reference sample and the sum of radioactivity recovered in all the organs and carcass were used to calculate cardiac output and regional blood flows (9). The left and right hemispheres of the brain and the left and right kidneys were carbonized and counted separately. No disparity of flow/g tissue between these paired organs was noted, despite the fact that the right carotid artery had been ligated to place the catheter in the left ventricle. Final data for brain include both cerebral hemispheres and the brain stem. The radioactivity of the isotopes was determined simultaneously and the counts were cross-channel corrected by a computer program using the appropriate pure isotope standards. All radiolabeled microspheres were assumed to have been trapped on the initial pass through the microcirculation (9). A single reference sample was drawn from the distal aorta because we and others have not detected right to left ductal shunts in this animal preparation (4).

All values are given as means \pm S.E. Comparisons between groups of lambs were made using Student's two tailed $t$ test. Significant differences in blood flow distributions were evaluated by an analysis of variance followed by the Student NewmanKeuls multiple comparison procedure.

\section{RESULTS}

The 18 lambs were divided retrospectively into two groups based on their respiratory status before treatment (Table 1). Group 1 contains those lambs with elevated $\mathrm{PCO}_{2}$ values before surfactant treatment whereas the lambs in group 2 had normal $\mathrm{PCO}_{2}$ values at treatment at $5 \mathrm{~h}$ of age. The blood gas and $\mathrm{pH}$ responses to surfactant therapy of the 2 groups are shown in Figure 1. The lambs in group 1 initially had more severe lung diesase with elevated $\mathrm{PCO}_{2}$ levels despite peak inspiratory pressures of $37.6 \pm$ $2.1 \mathrm{cmH}_{2} \mathrm{O}$. All eight lambs responded to surfactant instillation with a prompt increase in mean $\mathrm{Po}_{2}$ from 63 to over $200 \mathrm{mmHg}$. The surfactant therapy also resulted in a fall in $\mathrm{PCO}_{2}$ to a mean value of $43 \mathrm{mmHg}$ at $1 \mathrm{~h}$ after treatment, a concomitant rise in $\mathrm{pH}$ as a result of the decrease in $\mathrm{PCO}_{2}$, and an improvement in

Table 1. Characteristics of two groups of lambs

\begin{tabular}{lccc}
\hline & Group 1 & Group 2 & $P$ \\
\hline Number of lambs & 8 & 10 & \\
Gestational age (days) & $133.8 \pm 0.2$ & $134.8 \pm 0.3$ & $\mathrm{NS}^{2}$ \\
Weight (kg) & $2.4 \pm 0.2$ & $2.9 \pm 0.2$ & $\mathrm{NS}$ \\
$\mathrm{Sex} \mathrm{M/F}$ & $1 / 5^{1}$ & $5 / 5$ & \\
$\begin{array}{l}\text { Age at treatment with sur- } \\
\quad \text { factant (h) }\end{array}$ & $3.0 \pm 0.8$ & $5.1 \pm 0.1$ & $<0.01$ \\
$\mathrm{pH}$ before treatment & $7.15 \pm 0.02$ & $7.34 \pm 0.03$ & $<0.001$ \\
$\mathrm{PO}_{2}$ before treatment & $63 \pm 6$ & $237 \pm 37$ & $<0.001$ \\
$\quad(\mathrm{mmHg})$ & & & \\
$\mathrm{PcO}_{2}$ before treatment & $67 \pm 3$ & $38 \pm 1$ & $<0.001$ \\
$\quad(\mathrm{mmHg})$ & & & \\
$\begin{array}{l}\text { Peak inspiratory pressure at } \\
\text { treatment (cmH }\end{array}$ & $37.6 \pm 2.1$ & $25 \pm 1$ & $<0.001$ \\
\hline
\end{tabular}

\footnotetext{
${ }^{1}$ The sex was not recorded in two lambs.

${ }^{2} \mathrm{NS}$, not significant, $P>0.05$.
}

compliance (Fig. 2). The peak inspiratory pressure was not changed after treatment with surfactant (Fig. 2). Surfactant therapy did not permit a decrease of ventilatory suppport.

In contrast, lambs in group 2 required less peak inspiratory pressure before surfactant instillation to maintain good oxygenation and $\mathrm{PCO}_{2}$ values less than $40 \mathrm{mmHg}$. After surfactant instillation, the $\mathrm{PCO}_{2}$ increased slightly and the $\mathrm{pH}$ and compliance fell. An increase in peak inspiratory pressure was required to normalize the blood gas values (Fig. 2).

The cardiovascular status of both groups of lambs was remarkably stable despite surfactant instillation (Fig. 3). Lambs responding to surfactant treatment (group 1) had consistently lower mean blood pressures than group 2 lambs. Mean heart rates were not different between the two groups. The pulmonary artery pressures in the more acidotic lambs with lower $\mathrm{PO}_{2}$ values were not different than those measured in the group 2 lambs either before or $1 \mathrm{~h}$ after surfactant instillation. Pulmonary artery pressures appeared to fall transiently in group 1 lambs after instillation of surfactant. We observed very transient bradycardia and arrhythmias during and immediately after the surfactant instillation.

The cardiac outputs and distribution of blood flows in the two groups of lambs are given in Tables 2 and 3. Mean cardiac outputs in either group of lambs did not change after surfactant treatment. Blood flow to the heart, lungs, brain, and kidneys did not change after surfactant treatment. Of note was the large flow to the adrenal glands of both groups of lambs.

The flow to the lungs should be only from the bronchial circulation if the ductus arteriosus were fully constricted. Mean values of $29 \pm 9 \%$ and $25 \pm 8 \%$ of the left ventricular output of group 1 lambs went to the lungs before and after therapy, respectively. Four of these lambs had large left to right shunts with 50 $\pm 5 \%$ and $41 \pm 8 \%$ of the cardiac output entering the lungs before and after surfactant instillation, respectively; the other four lambs had only $8.2 \pm 2.3 \%$ of the cardiac output to the lungs. Mean values for $\%$ cardiac output directed to the lungs for group 2 lambs were $12.0 \pm 2.3 \%$ and $9.6 \pm 2.2 \%$ before and after treatment, respectively. These lambs had a constricted ductus with small or no shunts as pulmonary artery pressures were less than systemic pressures.

\section{DISCUSSION}

In several editorials, optimism has been expressed about the potential benefits of surfactant replacement therapy for RDS ( 2 , 19); however, the safety of administration of a relatively large volume of surfactant suspension into the airways remains a concern (15). Infants with RDS have very labile blood gases, and severe hypoxemia can occur with such routine nursing procedures as airway suctioning (14). The ability of the lungs of an infant with RDS to clear a bolus of fluid may also be less effective than in an infant without lung disease (16). Although the beneficial effects of surfactant suspensions given to infants (7) or lambs (1) with very severe lung disease may overcome any deleterious effects of the fluid volume, the fluid volume might be more detrimental to infants or premature animals with less severe degrees of lung immaturity.

In previously reported protocols using surfactant suspensions in prematurely delivered lambs, animals at 120-130 days gestational age have been used $(1,10,12)$. These lambs had a degree of pulmonary immaturity more severe than most infants with RDS. Ten of the lambs described in the present study (133-136 days gestational age) had a degree of respiratory failure at $5 \mathrm{~h}$ of age that was successfully treated to achieve normal $\mathrm{PCO}_{2}$ values with infant ventilators at peak inspiratory pressures of $25 \pm 1 \mathrm{cmH}_{2} \mathrm{O}$. We have documented that at this gestational age the pool size of surfactant disaturated phosphatidylcholine recovered by alveolar wash was proportionate to the peak inspiratory pressure that was needed to normalize the $\mathrm{PCO}_{2}$ values (11). Lambs that require about $25 \mathrm{cmH}_{2} \mathrm{O}$ peak inspiratory pressure would be expected to have surfactant pool sizes about $25-50 \%$ of that found in term newborn lambs (11); thus, these 10 lambs were assumed to have a mild form of a respiratory distress like syndrome. 


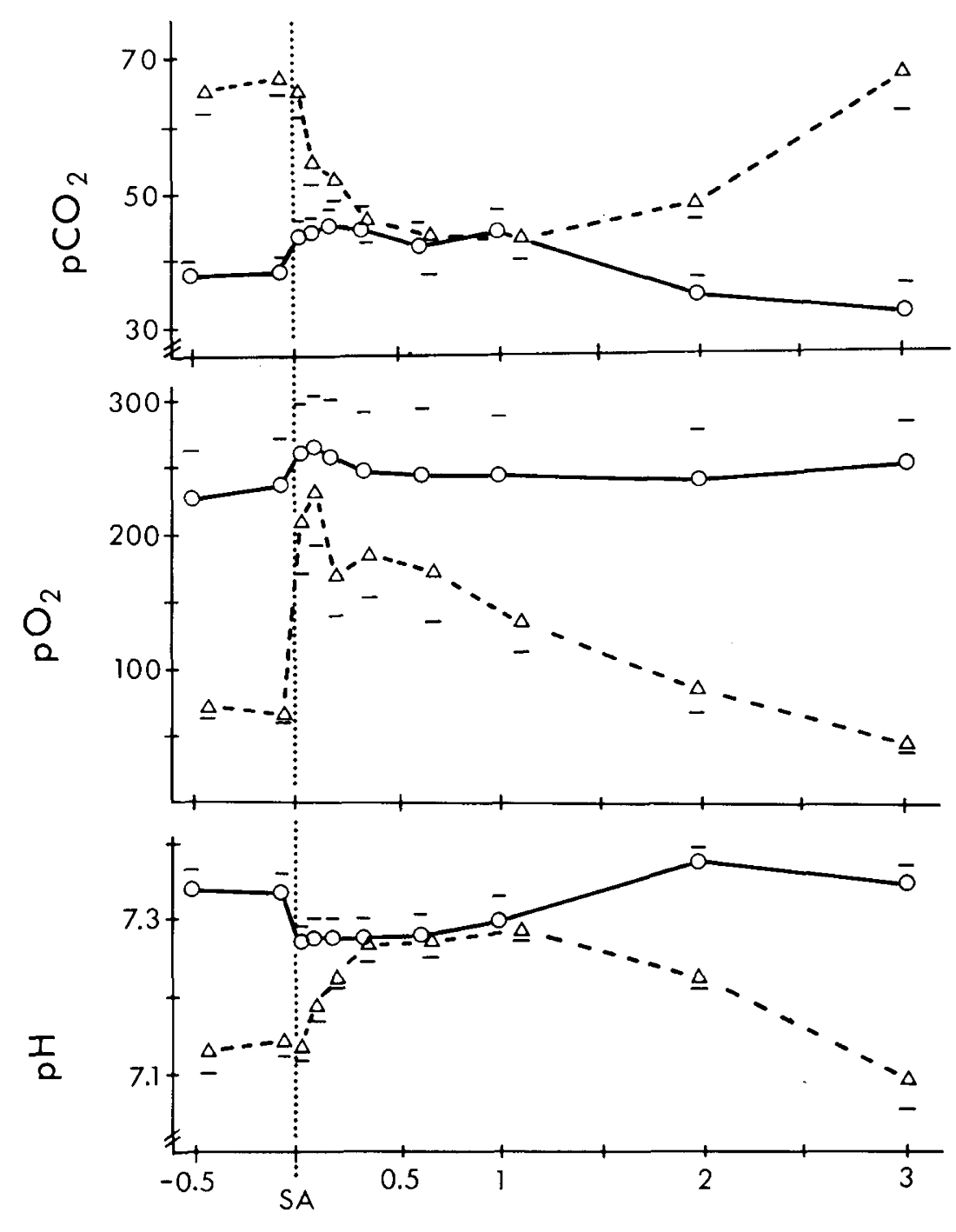

HOURS

Fig. 1. Blood gas and $\mathrm{pH}$ responses of lambs to surfactant suspensions. Mean \pm S.E. of $\mathrm{pH}, \mathrm{PO}_{2}$ and $\mathrm{PCO}_{2}$ in $\mathrm{mmHg}$ for the two measurements before and for $3 \mathrm{~h}$ after surfactant instillation (SA) are given. The time of SA instillation is given as time 0 and indicated by the vertical dotted line. The actual elapsed time from birth for SA instillation was $3.0 \pm 0.8 \mathrm{~h}$ for group 1 lambs $\left(\Delta_{-}-\Delta\right)$ and was $5.1 \pm 0.1$ for group 2 lambs $\left(O_{-}\right.$).

Eight lambs had lung disease characterized by elevated $\mathrm{PCO}_{2}$ values in spite of mean peak inspiratory pressures at $3 \mathrm{~h}$ of age of $37.6 \pm 2.1 \mathrm{cmH}_{2} \mathrm{O}$. Only lambs with elevated $\mathrm{PCO}_{2}$ values responded to the instillation of natural sheep surfactant with an improvement in lung function; however, the effect of the surfactant therapy was of short duration, as $\mathrm{PO}_{2}$ values fell and $\mathrm{PCO}_{2}$ values again increased within $3 \mathrm{~h}$ of treatment. We demonstrated previously that respiratory failure recurred after surfactant treatment of lambs delivered at 120 days gestational age concurrently with the measurement of elevated surface tensions in surfactant recovered by alveolar wash (10). The high minimum surface tensions seemed to result from the presence of soluble proteins that inhibited the ability of surfactant to lower the surface tension at an airwater interface (10).

Surfactant given to 10 lambs with normal $\mathrm{PCO}_{2}$ values did not result in any improvement in pulmonary function. In fact, we observed a small fall in compliance and an elevation of $\mathrm{PCO}_{2}$ values that returned to pretreatment values only after a mean increase in peak inspiratory pressure of $2 \mathrm{cmH}_{2} \mathrm{O}$. These lambs did not demonstrate the decrease in ventilatory support after surfactant administration that Fujiwara et al. (7) noted in infants with RDS; thus, there may be distinct differences in the responses of relatively mature lambs and infants to surfactant instillation. These observations in lambs suggest that one should be cautious about treating infants with surfactant suspensions unless the infants have relatively severe RDS.

Surfactant instillation did not result in large changes in the cardiovascular status of either group of lambs. Cardiac outputs before and about $20 \mathrm{~min}$ after surfactant treatment were not different. Although a large fall in cardiac output could have occurred immediately after surfactant instillation, the small changes in heart rates and systemic pressures suggest that cardiac output was preserved. The cardiac outputs and organ flows are very similar to the values reported by Furzan et al. (8) for healthy newborn lambs.

Mean pulmonary artery pressures were less than systemic pressures in both groups of lambs. Four of eight of the lambs who improved with surfactant therapy had large left to right shunts of cardiac output across a patent ductus arteriosus whereas none of the lambs with less severe lung disease had similarly large ductal shunts. Despite a rapid increase in $\mathrm{Po}_{2}$ and $\mathrm{pH}$ after surfactant instillation in the lambs with severe lung disease, no prolonged fall in mean pulmonary artery pressures occurred. After surfactant therapy initiated soon after birth in lambs delivered at 120 days gestational age, the left to right shunt across the ductus arteriosus increased (3). In the more mature lambs used in the present experiment, the mean shunt was similar before and after surfactant instillation. These results suggest that more mature animals may 


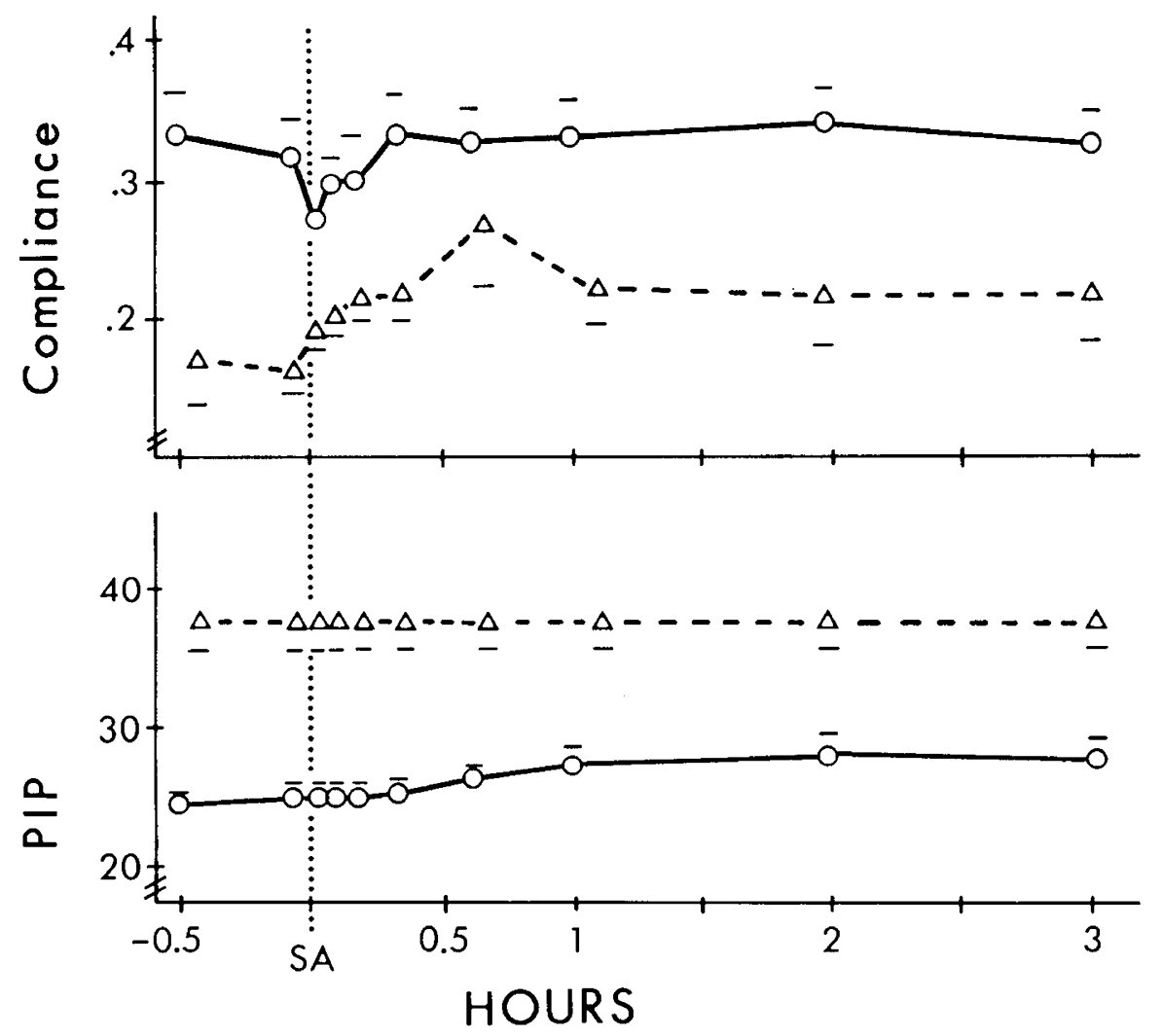

Fig. 2. Compliance and peak inspiratory pressures (PIP) of lambs. Mean \pm S.E. values are given for compliance/ $\mathrm{kg}$ body weight and PIP in $\mathrm{cmH} \mathrm{H}_{2} \mathrm{O}$ used to ventilate group 1 lambs $(\triangle--\triangle)$ and group 2 lambs $\left(\mathrm{O}_{-} \mathrm{O}\right)$. Surfactant instillation (SA) is indicated as time 0 by the vertical dotted line.

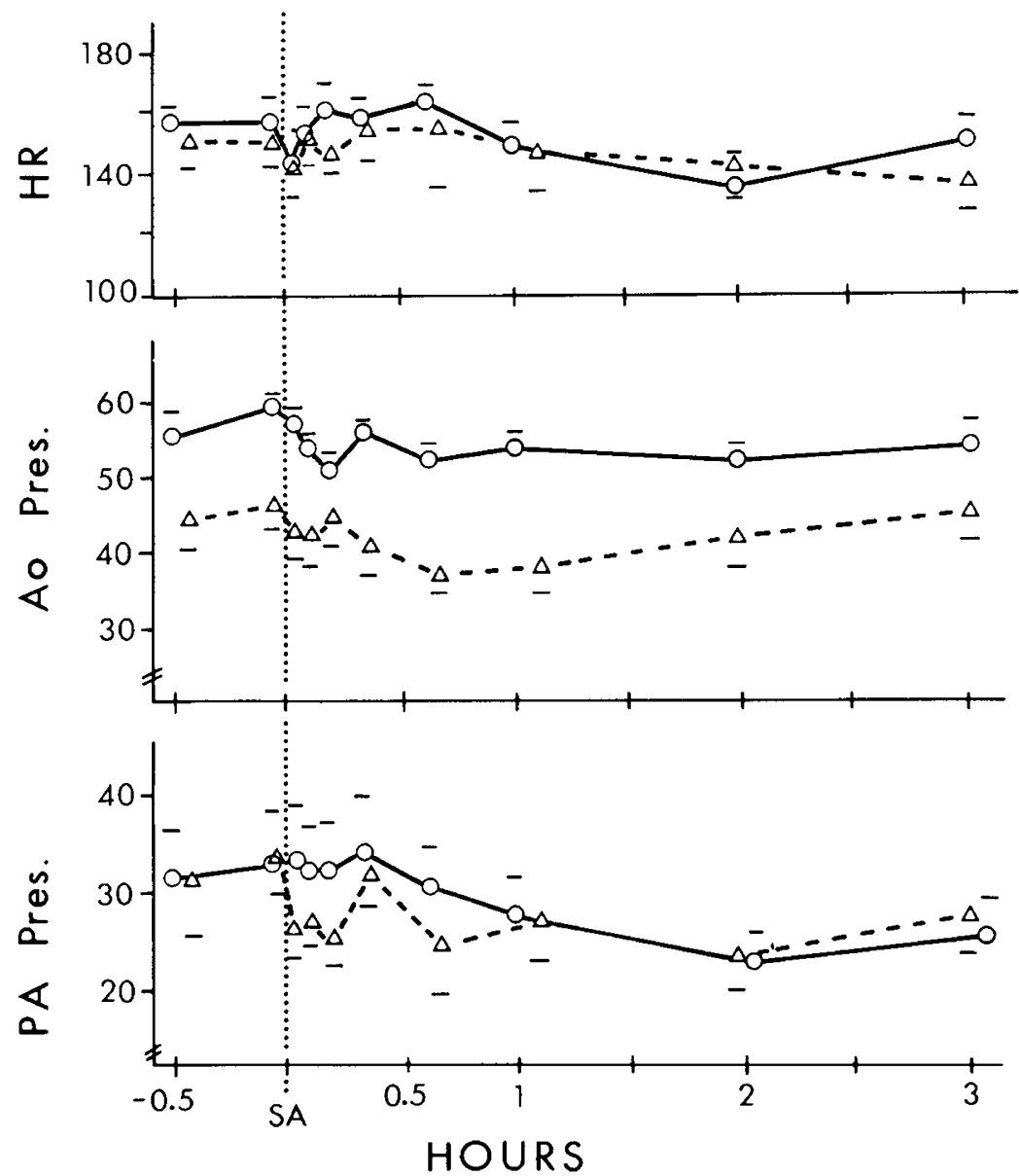

Fig. 3. Heart rates (HR), mean aortic pressures (Ao pres), and mean pulmonary artery pressures (PA pres) of lambs. Mean \pm S.E. values of HR in beats/min, Ao press and PA press in mmHg are shown for lambs tefore and for $3 \mathrm{~h}$ after surfactant instillation (SA) at time 0 (vertical dotted line). Group 1 lambs are indicated by $(\triangle--\triangle)$ and group 2 lambs are indicated by $\left(\mathrm{O}_{-} \mathrm{O}\right)$. 
Table 2. Cardiac output (C.O.) and blood flow in group 2 lambs

\begin{tabular}{lccc}
\hline & $\begin{array}{c}15 \pm 2 \mathrm{~min} \\
\text { before } \\
\text { surfactant } \\
(n=10)\end{array}$ & $\begin{array}{c}21 \pm 2 \mathrm{~min} \\
\text { after } \\
\text { surfactant } \\
(n=10)\end{array}$ & $\begin{array}{c}3 \mathrm{~h} \\
\text { after } \\
\text { surfactant } \\
(n=8)\end{array}$ \\
\hline $\begin{array}{l}\text { C.O./kg } \\
\text { cc/min/g tissue }\end{array}$ & $264.5 \pm 14$ & $236 \pm 16$ & $218 \pm 29$ \\
Carcass & $0.18 \pm 0.02$ & $0.15 \pm 0.01$ & $0.15 \pm 0.02$ \\
Heart & $1.62 \pm 0.25$ & $1.67 \pm 0.36$ & $1.53 \pm 0.35$ \\
Lung & $1.18 \pm 0.17$ & $0.96 \pm 0.29$ & $0.75 \pm 0.30$ \\
Brain & $0.50 \pm 0.07$ & $0.52 \pm 0.07$ & $0.41 \pm 0.08$ \\
Kidney & $1.38 \pm 0.26$ & $1.35 \pm 0.16$ & $0.71 \pm 0.13$ \\
G.I. & $0.69 \pm 0.08$ & $0.98 \pm 0.05$ & $0.93 \pm 0.15$ \\
Liver & $0.46 \pm 0.07$ & $0.39 \pm 0.06$ & $0.47 \pm 0.08$ \\
Adrenals & $4.47 \pm 0.42$ & $3.36 \pm 0.28^{1}$ & $3.54 \pm 0.54$ \\
Spleen & $4.57 \pm 1.07$ & $3.15 \pm 0.72$ & $1.78 \pm 0.49$ \\
\hline
\end{tabular}

${ }^{1} P<0.05$ versus before surfactant.

Table 3. Cardiac output (C.O.) and blood flow in group 1 lambs

\begin{tabular}{lcc}
\hline & $\begin{array}{c}8 \pm 1 \mathrm{~min} \\
\text { before surfactant } \\
(n=5)\end{array}$ & $\begin{array}{c}26 \pm 3 \text { min } \\
\text { after surfactant } \\
(n=5)\end{array}$ \\
\hline C.O./kg & $229 \pm 41$ & $203 \pm 16$ \\
cc/min/g tissue & & \\
Carcass & $0.10 \pm 0.03$ & $0.09 \pm 0.01$ \\
Heart & $2.31 \pm 0.89$ & $2.36 \pm 0.71$ \\
Lung & $1.28 \pm 0.72$ & $0.75 \pm 0.37$ \\
Brain & $0.96 \pm 0.27$ & $0.68 \pm 0.20$ \\
Kidney & $0.81 \pm 0.11$ & $0.85 \pm 0.05$ \\
G.I. & $0.47 \pm 0.11$ & $0.52 \pm 0.11$ \\
Liver & $0.41 \pm 0.05$ & $0.42 \pm 0.01$ \\
Adrenals & $7.20 \pm 2.22$ & $11.59 \pm 6.35$ \\
Spleen & $2.78 \pm 0.80$ & $0.77 \pm 0.29$ \\
\hline
\end{tabular}

be less sensitive to increased ductal shunting after surfactant treatments than more immature lambs. Surfactant instillations did not result in dramatic changes in the cardiovascular status of premature lambs at 133-136 days gestational age who were paralyzed and ventilated for lung immaturity.

Copyright (C) 1983 International Pediatric Research Foundation, Inc. 0031-3998/83/1706-0444\$02.00/0

\section{REFERENCES AND NOTES}

1. Adams, F. H., Tower, B., Osher, A., Ikegami, M., Fujiwara, T., and Nozaki, M.: Effects of tracheal instillation of natural surfactant in premature lambs. Pediatr. Res., 12: 841 (1978).

2. Avery, M. E.: On replacing the surfactant. Pediatrics, 65: 1176 (1980).

3. Clyman, R., Jobe, A., Heymann, M., Ikegami, M., Roman, C., Payne, B., and Mauray, F.: Increased shunt through the patent ductus arteriosus after surfactant replacement therapy. J. Pediatr., 100: 101 (1982).

4. Clyman, R. I., Mauray, F., Roman, C., Rudolph, A. M., and Heymann, M. A.: Circulating prostaglandin $E_{2}$ concentrations and patent ductus arteriosus in fetal and neonatal lambs. J. Pediatr., 97: 455 (1980).

5. Enhorning, G., Hill, D., Sherwood, G., Cutz, E., Robertson, B., and Bryan, C.: Improved ventilation of prematurely delivered primates following tracheal deposition of surfactant. Am. J. Obs. Gynecol., 132: 529 (1978).

6. Enhorning, G. and Robertson, B.: Lung expansion in the premature rabbit fetus after tracheal disposition of surfactant. Pediatrics, 50: 58 (1972).

7. Fujiwara, T., Chida, S., Watabe, Y., Maeta, H., Morita, T., and Abe, T.: Artificial surfactant therapy in hyaline-membrane disease. Lancet, $1: 55$ (1980).

8. Furzan, J., Gabriele, G., Wheeler, J., Fixler, D., and Rosenfeld, C.: Regional blood flows in newborn lambs during endotracheal continuous airway pressure and continuous negative pressure breathing. Pediatr. Res., 15: 874 (1981).

9. Heymann, M., Payne, B., Hoffman, J., and Rudolph, A.: Blood flow measurements with radionuclide-labeled particles. Prog. Cardiovasc. Dis., 20: 55 (1977)

10. Ikegami, M., Jobe, A., and Glatz, T.: Surface activity following natural surfactan treatment in premature lambs. J. Appl. Physiol., 51: 306 (1981).

11. Ikegami, M., Jobe, A., Jacobs, H., and Jones, S.: Surfactant pool sizes, inhibitors and the severity of respiratory distress syndrome in premature lambs. Pediatr. Res., 16: 35IA (1982).

12. Jobe, A., Ikegami, M., Glatz, T., Yoshida, Y., Diakomanolis, E., and Padbury, J.: Duration and characteristics of treatment of premature lambs with natural surfactant. J. Clin. Invest., 67: 370 (1981).

13. Johnson, J., Permutt, S., Sipple, J., and Salem, E. S.: Effect of intra-alveolar fluid on pulmonary surface tension properties. J. Appl. Physiol., 19: 769 (1964).

14. Long, J. G., Philip, A. G. S., and Lucey, J. F.: Excessive handling as a cause of hypoxia. Pediatrics, 65: 203 (1980).

15. Morley, C., Miller, N., Bangham, A., and Davis, J.: Dry artificial lung surfactant and its effect on very premature babies. Lancet 821l: 64 (1981).

16. Normand, I., Reynolds, E., Strang, L., and Wigglesworth, J.: Flow and protein concentration of lymph from lungs of lambs developing hyaline membrane disease. Arch. Dis. Child., 43: 334 (1968).

17. Smyth, J., Metcalfe, I., Duffty, P., Enhorning, G., Possmayer, F., Olley, P., and Bryan, M. H.: Surfactant therapy in hyaline membrane disease. Pediatr. Res., 15: 681 (1981)

18. Stahlman, M., LeQuire, V. S., Young, W. C., Merrill, R. E., Buckingham, R. T., Payne, G. A., and Gray, J.: Pathophysiology of respiratory distress in newborn lambs. Am. J. Dis. Child., 108: 375 (1964).

19. Wigglesworth, J. S.: Artificial surfactant therapy for hyaline membrane disease. Arch. Dis. Child., 55: 753 (1980).

20. Requests for reprints should be addressed to: Dr. Alan Jobe, Harbor-UCLA Medical Center, Bldg. A-17, Torrance, CA 90509.

21. This research was supported by Health and Human Development Grant HD12714 , by a grant from the March of Dimes-Birth Defects Foundation, and by a Research Carrer Development Award HD-HL-00252 to A.J.

22. Received for publication February 9, 1982.

23. Accepted for publication September 9,1982 